\title{
Seroprevalence of Brucella Agglutinins in Patients with Pyrexia of Unknown Origin Attending a Tertiary Care Rural Hospital
}

\author{
Smita Sachin Damke1 ${ }^{1}$ Sachin Gajanan Damke² \\ ${ }^{1}$ Department of Microbiology, JNMC, Wardha, Maharashtra, India. \\ 2Department of Paediatrics, JNMC, Wardha, Maharashtra, India.
}

\section{ABSTRACT}

\section{BACKGROUND}

Human brucellosis is a zoonosis with worldwide distribution, with great importance in developing countries like India. The diagnosis of brucellosis is frequently difficult to establish as it mimics many other infectious and non-infectious diseases. The use of feasible diagnostic tests seems to be great importance for diagnosing human brucellosis. The present study was carried out to study the seroprevalence of human brucellosis by estimating IgG and IgM by ELISA in central India.

\section{METHODS}

A total of 124 serum samples were collected over a period of one year, and processed in a tertiary care teaching hospital in central India. Serum samples of patients admitted to the hospital with the diagnosis of pyrexia of unknown origin (PUO) were investigated for detectable IgG and IgM antibodies by ELISA. The observance values thus obtained were converted to Nova Tec Unit (NTU) by using the formula according to the manufacturer's instructions.

\section{RESULTS}

Of the total of 124 serum samples, ELISA detected presence of IgG antibodies in 12 $(9.67 \%)$ indicating chronic infection and IgM antibodies in 28 (22.58\%) suggesting acute and recent infection.

\section{CONCLUSIONS}

ELISA has the ability to measure two specific immunoglobulins for effective diagnosis and is also a rapid method for detecting seroprevalence of human brucellosis in the community.

\section{KEY WORDS}

Brucella Antibodies, PUO, Pyrexia, Seroprevalence, ELISA
Corresponding Author: Smita Sachin Damke, Associate Professor, Department of Microbiology, JNMC, Wardha, Maharashtra, India. E-mail: smitasdamke@gmail.com

DOI: $10.14260 / \mathrm{jemds} / 2020 / 36$

Financial or Other Competing Interests: None.

How to Cite This Article:

Damke SS, Damke SG. Seroprevalence of Brucella agglutinins in patients with pyrexia of unknown origin attending a tertiary care rural hospital. J. Evolution Med. Dent. Sci. 2020;9(03):162-165, DOI: 10.14260/jemds/2020/36

Submission 18-09-2019,

Peer Review 02-01-2019,

Acceptance 09-01-2020,

Published 20-01-2020. 


\section{BACKGROUND}

Human brucellosis is a bacterial zoonosis reported from all over the world. The causative agent is Gram negative bacteria of genus Brucella, which are coccobacilli, non-sporing and noncapsulated. Humans can get infected with Brucella by the following routes; i) orally - consumption of raw or unpasteurized milk or contaminated dairy products and consumption of contaminated meat, ii) microbial inoculation through cuts or abrasions in the skin surface, conjunctival inoculation, iii) inhalation - of infectious aerosols. ${ }^{1}$

Human brucellosis is a systemic disease which varies from an acute febrile illness to a chronic, low grade ill-defined disease characterised by paucity of signs but may present with nonspecific symptoms as fever, nocturnal sweating, malaise, fatigue and myalgia. Patients are often labelled as pyrexia of unknown origin (PUO) and undergo various laboratory investigations which usually do not have tests for Brucella serology. It is also considered as the cause of fever of prolonged duration in endemic area and one of the important causes of PUO..$^{2,3}$ Also it has been observed that although being endemic in most of the developing countries, Brucella infection remains as undiagnosed and under reported. Brucella can be diagnosed in laboratory by various methods, however accurate and timely diagnosis of Brucella infection in human beings because of its nonspecific clinical manifestation and complexity of sero-diagnosis, remain a challenge to the clinicin. 4,5 Hence, for diagnosis of human brucellosis battery of tests are proposed that includes enzyme linked immunosorbent assay (ELISA) which has a good sensitivity and specificity. ${ }^{6}$

The serological investigation of the patient is of paramount importance for diagnosis of the disease and for the treatment of the patient. We undertook this study to determine seroprevalence of Brucella infection in patients of PUO attending a tertiary care rural hospital.

\section{METHODS}

The present cross sectional study was carried out in the tertiary care rural hospital for a period of one year. Ethical approval was taken from the Institutional Ethical Committee. We processed 124 serum samples for suspected Brucella infection in PUO cases. The serum samples were collected from the patients admitted and clinically diagnosed as PUO and were investigated in the department of Microbiology. The serum was collected by paramedical staff by taking consent of the patient using sterilized disposable syringe ( $5 \mathrm{ml}$ ) as per standard procedure. This serum sample were aliquot and stored at -20 degree $\mathrm{C}$ for further use. Those samples which were Widal positive were excluded for the study.

All the serum samples were subjected to ELISA for detection of IgG and IgM antibodies for human brucellosis. The ELISA testing for IgG and IgM against Brucella spp. was performed using commercially available kit procured from Nova Tec Immunodiagnostic GMBH. This kit determines IgM and IgG class of antibodies by enzyme immunoassay for the quantitative determination of Brucella in humans. All the steps of the assay were performed in the order given by the manufacturers' guidelines. The results were interpreted by measuring the absorbance of the well at $450 \mathrm{~nm}$. The absorbance value thus obtained were converted into Nova Tec Units (NTU) by using the formula according to the manufacturers' instruction.

Patient (mean) absorbance value $\times 10=$ Nova Tec Units (NTU) Mean absorbance value of cut off

The final result was given as value $>11$ was considered positive, $<9$ was considered negative and borderline results were retested and confirmed as either negative or positive. The diagnostic specificity and sensitivity provided with the manufacturer manual was $>95 \%$.

\section{Statistical Analysis}

The data was collected and analyzed using standard statistical chi - square test, $\mathrm{p}<0.05$ statistically significant. Data was entered in Microsoft excel and analysis was done using SPSS version 22.

\section{RESULTS}

The total of 124 serum samples were tested for human brucellosis. The patients included in the study from all the age groups that is from paediatrics to geriatrics. Of these males were $63(50.8 \%)$ and females were 61 (49.19\%). In the present study, ELISA detecting IgG and IgM antibodies were positive in $12(9.67 \%)$ and $28(22.58 \%)$ respectively. The positivity of Brucella antibodies in male patients for IgM and IgG were found to be $12(9.67 \%)$ and 7 (5.6\%) respectively. In the case of female patients, IgM antibodies were positive in 16 (12.9\%) and IgG antibodies were positive in 5 (4.03\%) (Table 1). Antibodies usually begin to appear in the blood at the end of first week of the disease, IgM appearing first followed by IgG. A total of $28(22.58 \%)$ serum samples showed presence of IgM antibodies suggesting acute or recent infection by Brucella species, whereas $12(9.67 \%)$ serum showed presence of IgG antibodies indicating chronic infection.

In the present study, only $1(0.8 \%)$ patient was positive for both the classes of immunoglobulins i.e. IgG and IgM. Eightyfive $(68.54 \%)$ were negative for both IgG and IgM.

\begin{tabular}{|c|c|c|c|c|}
\hline $\mathbf{n = 1 2 4}$ & \multicolumn{2}{|c|}{ Male (63) } & \multicolumn{2}{c|}{ Female (61) } \\
\hline & Positive & Negative & Positive & Negative \\
\hline IgM & $12(9.67 \%)$ & $51(41.12 \%)$ & $16(12.9 \%)$ & $45(36 \%)$ \\
\hline IgG & $7(5.6 \%)$ & $56(45.16 \%)$ & $5(4.03 \%)$ & $56(45.16 \%)$ \\
\hline \multicolumn{3}{|c|}{ Table 1. Distribution of Brucella IgM and IgG } \\
\hline
\end{tabular}

\section{DISCUSSION}

Brucellosis is considered as an important cause of PUO in endemic areas. Living in proximity to animals is a major risk factor for contracting the diseases. Human brucellosis is an infection with non-specific symptoms initially, and often not detected in earlier phases. ${ }^{7}$ Human brucellosis generally go unnoticed, undiagnosed by medical professionals owing to overlapping symptoms with other disease. The initial symptoms are vague and hence patients report late and are thus less likely to be diagnosed. Worldwide human Brucella 
infection is a key occupational anthropozoonosis which result in financial losses and social burden.

The diagnosis of brucellosis thus depends on clinicians' high index of suspicion which should be based on epidemiological information. Microbiological tests, serological tests or molecular methods are employed for confirmation of the diagnosis, each having its own advantages and disadvantages. Therefore, it is always recommended to use a battery of test in the diagnosis of brucellosis including Enzyme linked immunosorbent assay (ELISA) which is reported to be a sensitive and specific test. ${ }^{6}$ The advantages of serological tests are that they are rapid, simple, affordable and risk of infection for those involved in handling the specimens is negligent. These advantages explains their widespread use in recent years. Gomez et $\mathrm{al}^{8}$ assigned the sensitivity ELISA of $60 \%$ for IgM and $84 \%$ for IgG. A study by Mohraz et al, ${ }^{9}$ the sensitivity and specificity of IgG ELISA were 93\% and 100\%, respectively. The sensitivity of IgG ELISA in the study by Peeridogaheh et al ${ }^{10}$ was $75.4 \%$ which is less as compared to the studies done by Mohrazet al, ${ }^{9}$ (93\%) and Vakili et al. $(93.7 \%)^{11}$. However, the sensitivity of IgM ELISA in the study by Peeridogaheh et $\mathrm{al}^{10}$ was higher that is $40.6 \%$ than that in Vakili et al, ${ }^{11}(12.5 \%)$ study. The specificity of IgG ELISA of Mohrazet al, ${ }^{9}$ study (100\%) and IgM ELISA of Vakiliet al.,11 study $(100 \%)$ support the result of Peeridogaheh et al. ${ }^{10}$

It is observed that from the review of literature, that it is difficult to compare seroprevalence of brucellosis in different studies as it varies from place to place and time to time. Magnitude of human brucellosis differ from state to state in India. The diagnosis of human brucellosis depends on type of antigen, diagnostic techniques used and level of antibody titers considered as diagnostic in particular area. The selection criteria used for laboratory investigation for brucellosis also plays an important role in determining seroprevalence of brucellosis in particular geographical area. Bhat et al.12 reported a seroprevalence of $8.5 \%$ in the general population of Belgaum.

In patients with prolonged duration of fever, the seroprevalence of Brucella infection has been reported only in few studies. From north eastern Nigeria Baba et al. ${ }^{13}$ reported a seroprevalence of $5.2 \%$, from south eastern Ethiopia it was $3.6 \%$ by Tolosa et al. ${ }^{14}$ Among studies from India the seroprevalence reported is less; $0.8 \%$ from northern India Kashmir by Kadri et al. ${ }^{15}$ and $1.0 \%$ from Karnataka a southern state in India by by Aniyappanavar et al. ${ }^{16}$ who did his study among hospitalized patients with prolonged fever.

In 23 clinically suspected cases of brucellosis Mathai E et al. ${ }^{17}$ has reported 9 (39.1\%) samples positive for IgM and 3 for IgG by ELISA. In the present study, seroprevalence for IgM was found to be $22.5 \%$ and for IgG it was $9.6 \%$. The main drawback of serological tests, in endemic areas, is the low specificity levels as large proportion of the population may have persistent Brucella-specific antibodies. It is therefore important to establish a "normal range" for the population of endemic region. Although for the definitive diagnosis of human brucellosis it requires isolation of organism from blood or other body fluids and since Brucella are slow growing organisms and require special culture conditions ${ }^{18}$ and owing to the delay in the isolation, serological methods are required for rapid diagnosis.

\section{CONCLUSIONS}

The disease assumes importance as more than two thirds of the population in India live in rural areas that is constantly exposed to the infected animals which may result in continuous transmission of the Brucella infection to humans. The advantages of ELISA are that it can detect two specific antibodies against Brucella infection and also it is an effective, simple and rapid diagnostic tool. ${ }^{19,20,21}$ ELISA in diagnosis of brucellosis in endemic area could be useful as a screening test in areas with low incidence of disease. ${ }^{22}$

\section{REFERENCES}

[1] Wu G, Yang C, Li J, et al. Prevalence study of brucellosis among high risk people in Xinjiang region, China. Microbiology Discovery 2013;1:2.

[2] Alton GG, Forsyth JRL. Brucella. Chapter - 28. In: Samuel Baron's Medical Microbiology. $4^{\text {th }}$ edn. 1996. http://gsbs.utmb.edu/microbook/ch028.htm,

[3] Anand BR. Pyrexia of unknown origin in the Kashmir valley: a preliminary study of one year. Ind J Med Sci 1968;22 (10):702-8.

[4] Young EJ. An overview of human brucellosis. Clin Infect Dis 1995;21 (2):283-90.

[5] Alton GG, Jones LM, Pietze DE. Laboratory techniques in Brucellosis. World Health Organ Monograph ser No. 55, $2^{\text {nd }}$ edn. Geneva: WHO 1975: p. 1-163.

[6] Da Silva Mol JP, De Araujo FS, Da Paixao TA, et al. Laboratorial diagnosis of brucellosis. $\mathrm{R}$ Bras $\mathrm{Ci}$ Vet 2012;19 (3):117-26.

[7] Zhen Q, Lu Y, Yuan X, et al. Asymptomatic brucellosis infection in humans: Implications for diagnosis and prevention. Clin Microbiol Infect 2013;19 (9):395-7.

[8] Go'mez MC, Nieto JA, Rosa C, et al. Evaluation of seven tests for diagnosis of human brucellosis in an area where the disease is endemic. Clin Vaccine Immunol 2008;15 (6):1031-3.

[9] Mohraz M, Kariminia A, Sarafnejad A, et al. Evaluation of DOT-ELISA in diagnosis of Brucellosis in Imam Khomeini hospital, 2000. Iran J Infec Dis Trop Med 2003;23:10-13.

[10] Peeridogaheh H, Golmohammadi MG, Pourfarzi F. Evaluation of ELISA and Brucellacapt test for diagnosis of human brucellosis. Iran J Microbiol 2013;5 (1):14-8.

[11] Vakili Z, MomenHeravi M, Sharifi AR, et al. Sensitivity and specificity of ELISA test in diagnosis of brucellosis. Kowsar Med J 2010;15 (2):95-8.

[12] Bhat K, Hemashettar BM, Jain R, et al. Latex agglutination test for antigen detection in human brucellosis. Indian J Med Microbiol 1997;15:210-4.

[13] Baba MM, Sarkindared SE, Brisibe F. Serological evidence of brucellosis among predisposed patients with pyrexia of unknown origin in the North Eastern Nigeria. Cent Eur J Public Health 2001;9 (3):158-61.

[14] Tolosa T, Regassa F, Belihu K, et al. Brucellosis among patients with fever of unknown origin in Jimma University Hospital, South-western Ethiopia. Ethiop J Health Sci 2007;17 (1):1-6. 
[15] Kadri SM, Rukhsana A, Laharwal MA, et al. Seroprevalence of brucellosis in Kashmir (India) among patients with pyrexia of unknown origin. J Indian Med Assoc 2000;98 (4):170-1.

[16] Aniyappanavar D, Prasad SR, Tanveer KM, et al. Brucella infections in high-risk population and in patients hospitalized for fever: a serological study at Kolar, Karnataka. Ann Trop Med Public Health 2013;6 (5):54953.

[17] Mathai E, Singhal A, Verghese S, et al. Evaluation of an ELISA for the diagnosis of Brucellosis. Indian J Med Res 1996;103:323-4.

[18] Pascual E. Brucellar Arthritis. In: Maddison PI, Isenberg DA, Woo P, et al. eds. Oxford Textbook of Rheumatology. Oxford, UK: Oxford University Press 1993: p. 581-9.
[19] Osoba AO, Balkhy H, Memish Z, et al. Diagnostic value of Brucella ELISA IgG and IgM in bacteremic and nonbacteremic patients with brucellosis. J Chemother 2001;13 Suppl 1:54-9.

[20] Pappas G, Akritidis N, Bosilkovski M, et al. Brucellosis. N Engl J Med 2005;352 (22):2325-36.

[21] Araj GF. Human brucellosis: a classical infectious disease with persistent diagnostic challenges. Clin Lab Sci 1999;12 (4):207-12.

[22] Karplus R, Ramlawi A, Banai M, et al. The use of ELISA in a seroprevalence study of Brucella antibodies in West Bank Palestinian women in child bearing age. Int J Infect Dis 2007;11 (4):367-8. 